\title{
Clear Cell Adenocarcinoma of the Rectum
}

\author{
A.A. Mallik K.C. Katchy \\ Department of Pathology, Al-Sabah Hospital, Safat, Kuwait
}

\section{Key Words}

Clear cell adenocarcinoma - Intestinal neoplasm . Rectum • Metastasis · Young age · Female

\begin{abstract}
Objective: To document the first case of clear cell adenocarcinoma of the rectum (a rare entity) in Kuwait. Clinical Presentation and Intervention: A 36-year-old female presented with a 1-year history of constipation and bleeding per rectum. Colonoscopy revealed an ulcerated mass $2 \mathrm{~cm}$ above the anal verge. After multiple biopsies an abdomino-perineal resection was performed for the rectal mass. Gross examination of the resected specimen revealed an anorectal mass measuring $5 \mathrm{~cm}$ in its long axis. Histopathological examination showed the tumor to be composed of lobules of mostly clear polygonal cells with round vesicular nuclei. Glandular formation was occasional. The tumor was rich in glycogen, focally displayed luminal mucin, and was associated with regional lymph node metastasis. Conclusion: This report illustrates a case of intestinal clear cell adenocarcinoma with lymph node metastasis that suggested a poor prognosis.
\end{abstract}

\section{Introduction}

Clear cell carcinoma of the large intestine is a distinct histological entity whose clinical and epidemiological features have not been adequately studied because of its rarity. Since the initial report by Hellstrom and Fischer [1] in 1964, only 10 cases have been documented in the English literature to the best of the present authors' knowledge. Two of them were metastatic renal cell carcinomas, 1 of which appeared 7 years after nephrectomy for the primary tumor $[2,3]$ and the remaining 8 cases were primary intestinal tumors [4-10]. A correct identification of this entity is therefore important partly because of the necessity to differentiate it from other clear cell tumors which may be secondary at this site and partly because its ovarian metastasis may be mistaken for a primary ovarian tumor [10].

The objective of this report was to document the clinical and pathological features of the first case of clear cell carcinoma of the rectum diagnosed in Kuwait in 2000. The importance of recognizing it as a rare variant of primary intestinal carcinoma is highlighted.
Dr. Anupama Arora Mallik

Department of Pathology

Al-Sabah Hospital, PO Box 4078

Safat 13041 (Kuwait)

Tel./Fax+965 481 8541, E-Mail anupamamallik@hotmail.com 


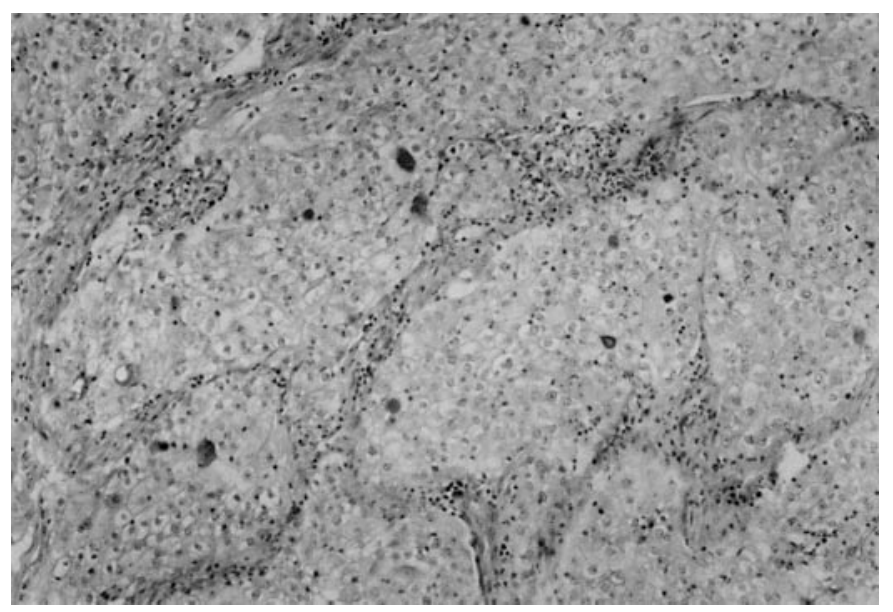

Fig. 1. Lobules of clear cells separated by fibrous septae. Hematoxylin-eosin. Original magnification $\times 100$.

\section{Case Report}

A 36-year-old Bangladeshi female came to the out-patient clinic with complaints of bleeding per rectum and constipation, associated with lower abdominal pain for 1 year. On defecation, not only did this pain increase, but she also felt a mass protrude through the anal canal. Although an impression of 3rd-degree piles was formed, rectal examination was deferred at this stage because of severe pain. A subsequent rectal examination, which was performed during admission, revealed a firm mass about $2 \mathrm{~cm}$ above the anal verge. Colonoscopy was performed. It revealed an ulcerated mass, about $2 \mathrm{~cm}$ above the dentate line, which extended from the 12 to 7 o'clock position. No other growth was found up to the splenic flexure. Computerized tomography scan of the pelvis showed a rectal mass with no extra-rectal or lymph node involvement. The other organs were normal. Following biopsy reports of an adenocarcinoma in the rectum, an abdominal perineal resection was performed. The post-operative course was uneventful. After discharge, the patient was lost to follow-up.

The surgical specimen consisted of sigmoid colon, rectum and anal canal measuring $19 \mathrm{~cm}$ in length. At a distance of about $2.5 \mathrm{~cm}$ above the anal verge, there was an ulcerated cauliflower mass measuring $5 \mathrm{~cm}$ on its longitudinal axis and distending the rectum. It involved the full thickness of the rectal wall. Five level 1 and three level 2 lymph nodes were identified.

Histological examination of both biopsy and the resected specimen showed a tumor entirely composed of polygonal or columnar cells arranged mostly in lobules separated by normovascular fibrous septae containing predominantly chronic inflammatory cells (fig. 1). Occasional glandular formation was present (fig. 2). The cells had well-defined borders, abundant cytoplasm and more or less uniform round to oval vesicular nuclei with 1-2 nucleoli (fig. 3). The cytoplasm varied from clear to basophilic or eosinophilic. Mitotic count was about 8 per 10 high-power fields. There was little evidence of a conventional adenocarcinoma or squamous differentiation.

The tumor was sharply demarcated from the transitional mucosa of the anal canal and extended into but not beyond the muscularis propria. All three level 2 lymph nodes contained tumor with identical

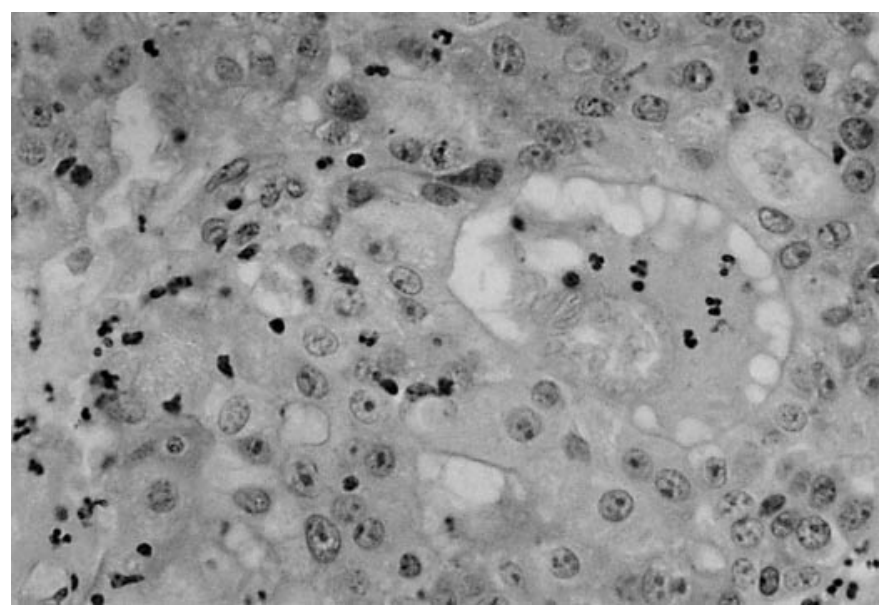

Fig. 2. Occasional gland formation. Hematoxylin-eosin. Original magnification $\times 400$.

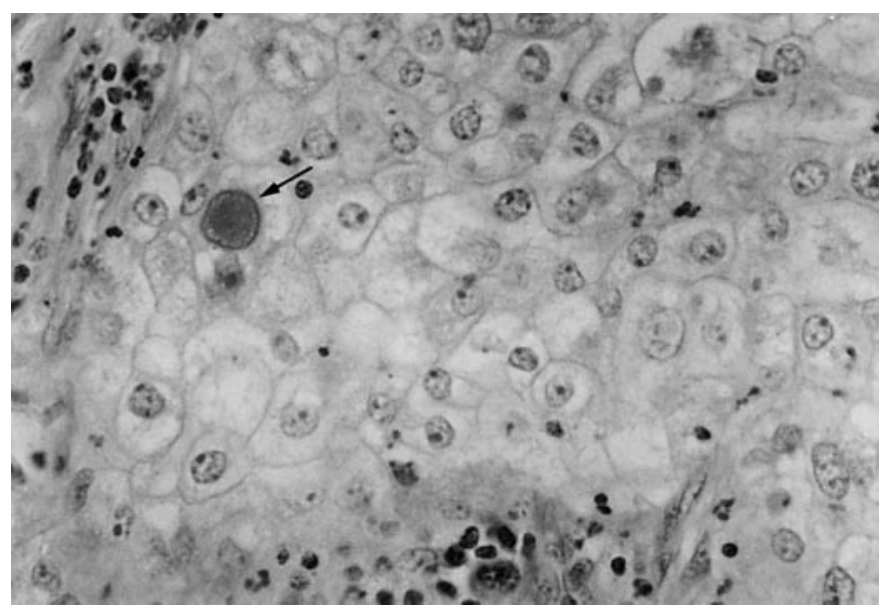

Fig. 3. High magnification view of the tumor showing nuclear and cytoplasmic detail. The arrow points to extracellular mucin. Hematoxylin-eosin. Original magnification $\times 400$.

histological features as in the rectum. The level 1 lymph nodes were free of tumor. A diagnosis of a clear cell adenocarcinoma of the rectum with regional lymph node metastasis was made.

Histochemically most of the tumor cells contained periodic-acidSchiff (PAS)-positive, diastase-labile granules and some basophilic material within intracellular and extracellular lumina. It stained positively with Alcian blue ( $\mathrm{pH} 2.5$ ), PAS with diastase treatment and mucicarmine. Immunohistochemically, the tumor cells were positive for carcinoembryonic antigen (DAKO, rabbit anti-human) and negative for CA 125 (Novocastra, monoclonal mouse anti-human). The antibody to epithelial membrane antigen (DAKO, monoclonal mouse antihuman) highlighted the intracellular lumina containing the basophilic material. 


\section{Discussion}

Clear cell carcinomas of the large intestine are extremely rare. The young age (36 years) of the patient in this case report is noteworthy. Conventional rectal carcinomas tend to occur at an older age. On the other hand, endometriosis affects women in childbearing age and clinically may simulate an intestinal neoplasm. Significantly, 2 cases of clear cell carcinoma of the colon reported by McCluggage et al. [8] and Hitti et al. [9] were associated with intestinal endometriosis. There was no evidence of endometriosis in the present case.

Glycogen accumulation [4] or presence of apparently empty vacuoles [6] has been shown to cause cytoplasmic clearing in these tumors. The result of histochemistry in this case indicates that the cytoplasmic clearing was a manifestation of intracellular accumulation of glycogen. The focal presence of intracellular luminal mucin is considered a significant finding for two reasons. First, it is the first such documentation in these tumors. Secondly, it is useful in excluding metastasis from the kidney and genital tract. Clear cell tumors of these organs, with similar histological picture, do not usually have intracellular luminal mucin. Indeed this finding suggests that the tumor may be primary at this site.
Consistent with other reports, the present tumor lacked the hypervascularity usually seen in renal clear cell carcinoma. The immunohistochemical, radiological and intra-operative findings in this case further strengthened the diagnosis of a primary rectal clear cell carcinoma.

Although the mass was encroaching on the anal canal the possibility of an adenosquamous carcinoma arising from the anal canal and extending to the rectum was discounted because of lack of squamous differentiation.

The loss of this patient to follow-up precludes any determination of the final outcome. However, the extent of the disease (Astler and Coller-C1) [11] suggests a relatively bad prognosis. Although it appears from the few cases so far reported that the behavior of this tumor does not significantly differ from that of conventional intestinal carcinomas, a definite pronouncement cannot be made on this until more cases are evaluated.

\section{Conclusion}

This report illustrates a case of intestinal clear cell adenocarcinoma with lymph node metastasis that suggested a poor prognosis.

\section{References}

$>1$ Hellstrom HR, Fischer ER: Physaliferous variant of carcinoma of colon. Cancer 1964;17: 260-263.

$\checkmark 2$ Zerbib F, Becouam Y, Stockle E, Ravaud A, Brunet R: Colonic metastasis of a renal carcinoma; A case report. Tumori 1992;78:219220 .

$>3$ Tokonabe S, Sugimoto M, Komine Y, Horii H, Matsukuma S: Solitary colonic metastasis of renal cell carcinoma seven years after nephrectomy: A case report. Int J Urol 1996;3:501503 .
Jewell LD, Barr JR, McCaughey WT, Nguyen GK, Owen DA: Clear-cell epithelial neoplasms of the large intestine. Arch Pathol Lab Med 1988;112:197-199.

5 Reed RJ, Love GL, Harkin JC: Consultation case. Am J Surg Pathol 1983;7:597-601.

6 Rubio CA: Clear cell adenocarcinoma of the colon. J Clin Pathol 1995;48:1142-1144.

7 Watson PH: Clear-cell carcinoma of the anal canal: A variant of anal transitional zone carcinoma. Case studies. Hum Pathol 1990;21:350352.

8 McCluggage WG, Desai V, Toner PG, Calvert $\mathrm{CH}$ : Clear cell adenocarcinoma of colon arising in endometriosis: A rare variant of primary colonic adenocarcinoma. J Clin Pathol 2001; 54:76-77.
Hitti IF, Glasberg SS, Lubicz S: Clear cell carcinoma arising in extra ovarian endometriosis: Report of three cases and review of the literature. Gynecol Oncol 1990;39:314-320.

10 Young RH, Hart WR: Metastatic intestinal carcinomas simulating primary ovarian clear cell carcinoma and secretory endometrioid carcinoma: A clinicopathologic and immunohistochemical study of five cases. Am J Surg Pathol 1998;22:805-815.

11 Astler VB, Coller FA: The prognostic significance of direct extension of carcinoma of the colon and rectum. Ann Surg 1954;139:846. 